\title{
Pathways of Glucose Assimilation in Puccinia graminis
}

\author{
By J. M. MANNERS, * D. J. MACLEAN AND K. J. SCOTT \\ Department of Biochemistry, University of Queensland, St. Lucia, Queensland 4067, Australia
}

(Received 1 February 1982; revised 13 April 1982)

\begin{abstract}
[U- $\left.{ }^{14} \mathrm{C}\right]-\mathrm{D}-$ Glucose ( 1 and $20 \mathrm{~mm}$ ) was added to glucose-grown suspension cultures of Puccinia graminis, and the sequence of movement of the label into metabolic intermediates was determined under steady-state conditions. Radioactive label moved most rapidly into cellular pools of free glucose, amino acids and phosphate esters of trehalose and glucose, and less rapidly into free fructose. No lag was detected in the movement of label into any of these compounds. Thus fructose was the first free carbohydrate synthesized from glucose. Radioactive label moved more slowly, and with an initial lag phase, into trehalose, glucitol and mannitol; the lag was more pronounced for mannitol than glucitol. Kinetic data and specific activity measurements to identify precursors suggest that trehalose was formed via trehalose phosphate, mannitol via fructose, and glucitol via both glucose and fructose. Steady-state specific activities of all free intracellular carbohydrates were much lower (15-50\%) than that of the exogenous glucose, indicating that unlabelled carbon was entering these pools from storage reserves or other components from the culture medium.
\end{abstract}

\section{INTRODUCTION}

After infection of plants by rust fungi, photosynthates are rapidly converted to fungus-specific products such as sugar alcohols and trehalose (Smith et al., 1969; Lewis, 1976). However, metabolic pathways for the synthesis and utilization of these compounds are experimentally difficult to determine in infected plant tissue. Axenic cultures present the simplest system to characterize fungal metabolism, and thus provide a rational basis for future investigations of parasitically growing mycelium (Maclean, 1982).

Some progress has already been made on the carbohydrate metabolism of Puccinia graminis in axenic culture. Thus, Maclean \& Scott (1976) identified glucitol and ribitol as metabolites after growth on glucose; these compounds have rarely been reported as metabolites of other fungi (Pfyffer \& Rast, 1980a, b; Maclean, 1982). Maclean \& Scott (1976) suggested that glucitol might be formed by the direct reduction of glucose, as part of a novel pathway for the assimilation of glucose by this fungus. Experiments described in this paper have tested this hypothesis.

Several options are available when designing experiments to elucidate metabolic pathways. For example, the pathways of carbon assimilation in photosynthesis were determined firstly from $\left[{ }^{14} \mathrm{C}\right]$ carbon dioxide labelling experiments in vivo, followed by the detection and characterization of the necessary enzyme systems. Despite the obvious advantages of such kinetic labelling experiments in defining the direction of carbon flow during metabolism, there are surprisingly few reports of this type on the assimilation of exogenous sugars by fungi. Thus, a kinetic approach was adopted in this investigation, to detect the movement of label from exogenous [U-14 C]-D-glucose through sequential pools of metabolites in $P$. graminis.

\section{METHODS}

Growth of cultures. Strain VIB of Puccinia graminis f.sp. tritici, isolated from race 126-ANZ-6,7 by Maclean \& Scott (1970) was used for all experiments. The growth characteristics of this particular strain in axenic culture have been described by Maclean (1974). Liquid suspension cultures (unshaken) were maintained in the growth medium 
of Howes \& Scott (1973), viz. Czapek's minerals, 10 mM-tri-sodium citrate, $1 \%$ (w/v) Evan's peptone (Glaxo) and $2 \cdot 1$ mM-histidine- $\mathrm{HCl}$ at $\mathrm{pH} 6.0$ with $212 \mathrm{~mm}$-D-glucose. Cultures were fragmented and transferred to fresh medium (Howes \& Scott, 1973) at intervals of 3 weeks and were removed for experiments $12 \mathrm{~d}$ after transfer. Asepsis was maintained in all experiments; stock cultures were maintained at $23^{\circ} \mathrm{C}$.

${ }^{14} \mathrm{C}$ Labelling experiments. Cultures $(400 \mathrm{ml})$ were pooled and filtered on a glass fibre disc $(60 \mathrm{~mm}$ diam. Whatman GF/A) and washed four times with $150 \mathrm{ml}$ glucose-free growth medium. The mycelium was resuspended in $150 \mathrm{ml}$ growth medium containing lowered glucose concentrations ( 2 or $20 \mathrm{~mm})$. Three $50 \mathrm{ml}$ fractions were dispensed separately into $250 \mathrm{ml}$ conical flasks, and incubated at $26^{\circ} \mathrm{C}$ with gentle agitation for $18 \mathrm{~h}$. Two of these flasks, A and B, were used to estimate the total carbohydrate pools of the fungus by GLC and the remaining flask, $\mathrm{C}$, was used for ${ }^{14} \mathrm{C}$ labelling experiments.

To estimate total mycelial carbohydrate pools, a $20 \mathrm{ml}$ sample was taken from both flasks A and B at the beginning and end of each $3 \mathrm{~h}$ feeding experiment. Each sample was washed five times with $10 \mathrm{ml}$ double distilled water at $4{ }^{\circ} \mathrm{C}$ by filtration on glass fibre discs (wash time under $30 \mathrm{~s}$ ) and the mycelium and discs were placed in boiling $80 \%(\mathrm{v} / \mathrm{v})$ ethanol prior to analysis by GLC.

[U-14 C]-D-Glucose $\left(500-700 \mu \mathrm{Ci} ; 260 \mathrm{mCi} \mathrm{mmol}^{-1}, 9 \cdot 62 \mathrm{GBq} \mathrm{mmol}^{-1}\right)$ was added to flask $\mathrm{C}$ and samples $(2-10$ $\mathrm{ml}$ ) were removed after various time intervals. Each sample of mycelium was washed with cold water and placed in boiling $80 \%$ ethanol, as for flasks $\mathrm{A}$ and $\mathrm{B}$. To estimate the specific activity of the ambient $\left[{ }^{14} \mathrm{C}\right] \mathrm{glucose}$ in the medium, a $0.5 \mathrm{ml}$ sample was taken after $10 \mathrm{~min}$ incubation and centrifuged at $2000 \mathrm{~g}$ for $4 \mathrm{~min}$. The mycelial pellet was discarded and the supernatant stored at $-20^{\circ} \mathrm{C}$ until analysed using methods described below. To estimate mycelial dry weight, two $4 \mathrm{ml}$ samples were each filtered on to a pre-weighed Millipore filter (pore size $0 \cdot 8$ $\mu \mathrm{m}$ ) previously dried for $30 \mathrm{~h}$ at $80^{\circ} \mathrm{C}$. These were washed once with $5 \mathrm{ml}$ water, dried at $80^{\circ} \mathrm{C}$ for $48 \mathrm{~h}$ and weighed.

Analysis of ${ }^{14} \mathrm{C}$-labelled extracts. All mycelial samples were homogenized in $80 \%$ ethanol in a Ten Broeck hand homogenizer, the insoluble material was separated by centrifugation $(2000 \mathrm{~g})$ and washed three times with $80 \%$ ethanol. Insoluble fractions were resuspended in $1 \mathrm{ml} 80 \%$ ethanol and mixed with $10 \mathrm{ml}$ of scintillant solution $(4 \mathrm{~g}$ PPO $1^{-1}, 50 \mathrm{mg}$ POPOP $1^{-1}, 33 \%(\mathrm{v} / \mathrm{v})$ Triton X-100 in toluene) and the radioactivity was estimated; counts were standardized by the channels ratio method. The ethanol-soluble fractions were evaporated to dryness at $50{ }^{\circ} \mathrm{C}$ and $5 \mathrm{ml}$ water added to each followed by $5 \mathrm{ml}$ redistilled carbon tetrachloride to extract lipids; the aqueous and organic layers were separated and the process was repeated three times. The lipid fractions were pooled and evaporated to dryness in a scintillation vial, $10 \mathrm{ml}$ scintillant solution was added and the radioactivity was estimated. The aqueous fraction was separated into neutral, anionic and cationic fractions by ion exchange chromatography as described by Neal $\&$ Beevers (1961). The fractions were evaporated to dryness, taken up in $1 \cdot 5$ $\mathrm{ml}$ water and $25 \mu \mathrm{l}$ was removed for scintillation counting.

Neutral fractions were analysed by descending paper chromatography for 40-50 h on Whatman no. 1 paper with ethyl methyl ketone/acetic acid/boric acid-saturated water $(9: 1: 1$, by vol.) (Solvent 1 , Rees $\&$ Reynolds, 1958). The solvent which had dripped from the end of each chromatogram was collected to estimate radioactivity in highly mobile compounds. In some instances, papers were washed prior to chromatography with each of $0.5 \%$ (w/v) EDTA, water and redistilled ethyl acetate. Radioactivity on the chromatograms was determined by cutting them into $5 \mathrm{~mm}$ strips and counting these directly in a detergent-free scintillant $\left(4 \mathrm{~g} \mathrm{PPO} \mathrm{l}^{-1}, 50 \mathrm{mg}\right.$ POPOP $\mathrm{I}^{-1}$ in toluene). It was sometimes necessary to rechromatograph samples, in which case strips were recovered from the scintillant, washed twice with toluene, dried and eluted with water. The eluate was evaporated to dryness after six successive additions of $2 \mathrm{ml}$ methanol (to remove residual boric acid), and the sugars then dissolved in water.

Anionic fractions were initially analysed by descending paper chromatography for $30 \mathrm{~h}$ using ethyl acetate/acetic acid/formic acid/water (18:3:1:4, by vol.) (Solvent 2, Hough \& Jones, 1962). Radioactive areas on the chromatogram were located with a Nuclear Chicago paper strip counter and those on or close to the origin (putative sugar phosphates and organic acids) were then eluted from the paper, evaporated to dryness and taken up in $200 \mu \mathrm{l}$ alkaline phosphatase solution ( 20 units $\mathrm{ml}^{-1}$, Sigma, Escherichia coli origin) in $25 \mathrm{~mm}$-glycine/ $\mathrm{NaOH}$

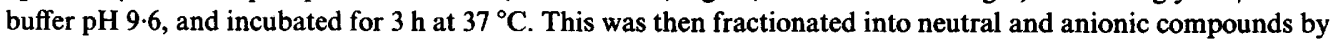
passing through $2 \mathrm{~g}$ Dowex 1-X2 (100-200 mesh, acetate form). Neutral compounds were washed from the resin with water and anions subsequently eluted with $20 \mathrm{ml} 2 \mathrm{M}$-formic acid. The neutral and anionic fractions obtained were then analysed by further paper chromatography as described above.

Cationic fractions were analysed by ascending paper chromatography (Whatman, no. 1) using phenol/water $(3: 1, \mathrm{v} / \mathrm{v})$ (Solvent 3 ), and radioactivity was determined in $5 \mathrm{~mm}$ strips as above. Authentic standards were run on all paper chromatograms, and were detected by the following methods: (1) sugars, polyols and gluconate by the alkaline silver oxide method of Trevalyan et al. (1950); when necessary papers were pretreated with hydrofluoric acid to remove boric acid (Britton, 1959); (2) amino acids by the ninhydrin method (Harborne, 1973) and (3) organic acids with bromothymol blue (Harborne, 1973).

Quantitative analysis of soluble carbohydrates by GLC. Compounds soluble in $80 \%$ ethanol were extracted from mycelium and lipids were removed as described above. Aqueous extracts or media samples were then deionized by shaking for 10 min with mixed ion exchange resins ( $1 \mathrm{~g}$ each of Bio-Rad AG 50 hydrogen form and Amberlite IR- 
45 free base form). Beads of resin were removed by centrifugation, washed three times with water and the supernatants pooled. Each deionized extract was divided into two fractions of equal volume. One fraction was evaporated to dryness, redissolved in $0.425 \mathrm{ml}$ redistilled pyridine and trimethylsilyl (TMS) ethers of soluble carbohydrates (Sweeley et al., 1963) prepared by addition of $50 \mu$ l hexamethyldisilazane followed by $25 \mu \mathrm{l}$ trimethylchlorosilane. Suitable standards were prepared similarly and all vials were left overnight at $26^{\circ} \mathrm{C}$. GLC of the TMS ethers was performed on a Shimadzu gas chromatograph model GC-6AM with a glass column (1.5 m $\times 3 \mathrm{~mm}$ i.d.) of $2 \%$ SE52 on dimethylchlorosilane-treated acid-washed Chromosorb W (mesh size 100-120, JohnsManville), attached to a flame ionization detector. The following programme was used, $\mathrm{N}_{2}$ carrier gas at $30 \mathrm{ml}$ $\mathrm{min}^{-1}$, injection port temperature at $260{ }^{\circ} \mathrm{C}$ and the column temperature increased at $6{ }^{\circ} \mathrm{C} \mathrm{min}^{-1}$ from $115^{\circ} \mathrm{C}$ to $290^{\circ} \mathrm{C}$. TMS ethers were quantified by comparing peak heights with those of standards. Isomeric hexitols were quantified by GLC of acetate derivatives using the remaining half of the deionized extracts. The extract was reduced to $2 \mathrm{ml}$ and $2 \mathrm{~g}$ Dowex 1-X8 (hydroxide form, 50-100 mesh) was added and the mixture was incubated at $100^{\circ} \mathrm{C}$ with constant agitation for $20 \mathrm{~min}$. Similar treatment of standards showed that this degrades and removes any aldose or ketose sugars present in the extract (Maclean \& Scott, 1976). The resin was separated and washed with water three times by centrifugation, the supernatants pooled, reduced to dryness and the residue of polyols redissolved in $250 \mu \mathrm{l}$ each of acetic anhydride and pyridine, and the mixture left overnight at $37^{\circ} \mathrm{C}$. Samples were then evaporated to dryness at $55-60^{\circ} \mathrm{C}$ in vacuo and redissolved in $100 \mu \mathrm{l}$ redistilled carbon tetrachloride. GLC was performed on a glass column $(3 \mathrm{~m} \times 3 \mathrm{~mm}$ i.d.) containing a stationary phase of Celite (100-120 mesh) coated with a mixture of $0.5 \% \mathrm{SE} 52$ and $6.0 \% \mathrm{OV} 275$, a nitrogen flow rate of $40 \mathrm{ml} \mathrm{min}^{-1}$, injection port temperature of $250{ }^{\circ} \mathrm{C}$

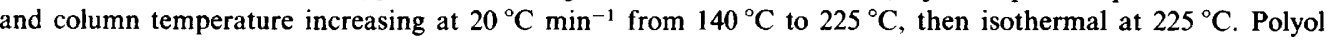
acetates were quantified by comparison of peak areas with those of standards.

\section{RESULTS}

\section{Overall distribution of radioactivity from $\left[{ }^{14} \mathrm{Clglucose}\right.$}

Analysis of the medium by GLC showed that during the $18 \mathrm{~h}$ preincubation, less than $5 \%$ of the initial $20 \mathrm{~mm}$-glucose was utilized, whereas $2 \mathrm{~mm}$-glucose was reduced to $1.05 \mathrm{~mm}$. Thus, labelling experiments were effectively carried out in either 1 or $20 \mathrm{~mm}$ glucose. Uptake rates after addition of label were linear: 0.078 and $0.51 \mathrm{nmol}(\mathrm{mg} \text { dry wt) })^{-1} \mathrm{~min}^{-1}$ for mycelium in 1 and $20 \mathrm{~mm}$ glucose, respectively.

Because the kinetics of labelling of the major metabolite pools were very similar with both glucose concentrations (Fig. 1) they are described together. $\left[{ }^{14} \mathrm{C}\right]$ Glucose was rapidly metabolized to anions and cations, each of which constituted $16-20 \%$ of the total ${ }^{14} \mathrm{C}$ assimilated after only $2 \mathrm{~min}$. The proportion of label located in cations increased considerably during the first $20 \mathrm{~min}$ with a concomitant reduction in the label present in neutral compounds; little change was observed thereafter. In later samples $37-38 \%$ of the total incorporated radioactivity was recovered in neutral compounds and $30-34 \%$ in cations. However, the proportion of label in anions declined very slowly to approximately $12 \%$ after $3 \mathrm{~h}$. Insoluble

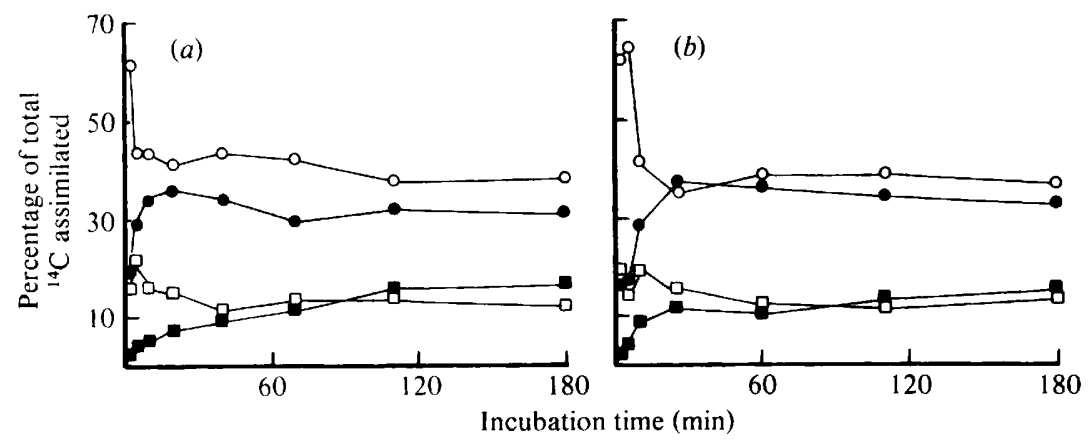

Fig. 1. Distribution of radioactivity between classes of compounds extracted from $P$. graminis after incubation in $(a) 1 \mathrm{~mm}$ exogenous $\left[{ }^{14} \mathrm{C}\right]$ glucose or in $(b) 20 \mathrm{~mm}$ exogenous $\left[{ }^{14} \mathrm{C}\right]$ glucose (see Methods for experimental details). Compounds insoluble in $80 \%$ ethanol. The following compounds soluble in $80 \%$ ethanol: $\bigcirc$, neutral compounds; $\odot$, cations; $\square$, anions. 
compounds constituted less than $3 \%$ of the total incorporated radioactivity after $2 \mathrm{~min}$, followed by an increase to $15-17 \%$ by $3 \mathrm{~h}$. Label in lipids never exceeded $1 \%$ of the total.

\section{Incorporation of radioactivity into neutral sugars and polyols}

Chromatography of neutral fractions on unwashed Whatman no. 1 paper using Solvent 1 clearly separated trehalose, glucose and fructose, and gave a single spot of putative hexitols (Fig. $2 a$ ). Although the putative hexitols (shaded region in Fig. $2 a$ ) were not as mobile as adjacent standards of D-mannitol and D-glucitol, analyses by GLC indicated that both were present in the mycelium. The putative hexitols were eluted, and rechromatographed on prewashed papers in the same solvent system after removal of boric acid from the sample and the addition of $100 \mu \mathrm{g}$ each of unlabelled D-mannitol and D-glucitol as cold carriers, thus demonstrating label in mycelial mannitol and glucitol (Fig. $2 b$ ). Negligible radioactivity was detected in compounds more mobile than hexitols.

Analysis of neutral sugars and polyols showed that after $2 \mathrm{~min}$, more than $50 \%$ of total incorporated label was present in glucose (Fig. 3) with smaller proportions in fructose $(5-6 \%$ ), trehalose $(2-4 \%)$ and hexitols $(0 \cdot 9-1 \cdot 5 \%)$. The proportion of label in glucose then dropped rapidly reaching $3 \%$ after $3 \mathrm{~h}$, whilst the label in fructose increased during the first $10 \mathrm{~min}$ to 7 $8 \%$, followed by a decline to $2 \%$ after $3 \mathrm{~h}$. After a short lag (see below), label increased rapidly in trehalose and glucitol, reaching a maximum of $18-23 \%$ in trehalose and $10-12 \%$ in glucitol after

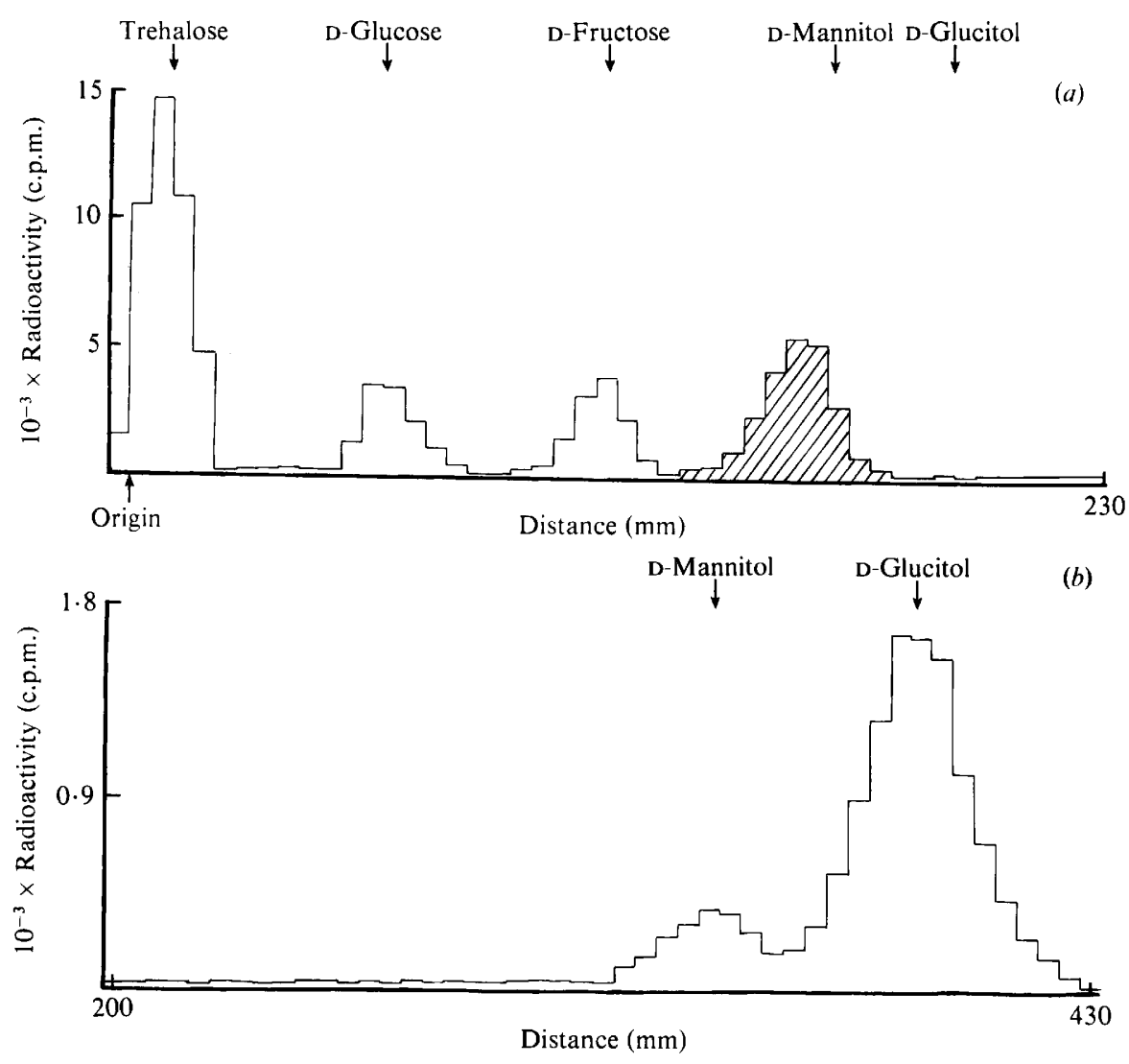

Fig. 2. Chromatographic separation of ethanol-soluble neutral compounds from extracts of $P$. graminis after $20 \mathrm{~min}$ incubation in $1 \mathrm{~mm}\left[{ }^{14} \mathrm{C}\right]$ glucose. $(a)$ Initial chromatographic separation using unwashed Whatman no. 1 paper and Solvent 1. $(b)$ Radioactivity in the shaded peak of $(a)$ was eluted and rechromatographed using the same solvent on washed Whatman no. 1 paper. The positions of authentic standards run on the same chromatograms are indicated by the arrows. 


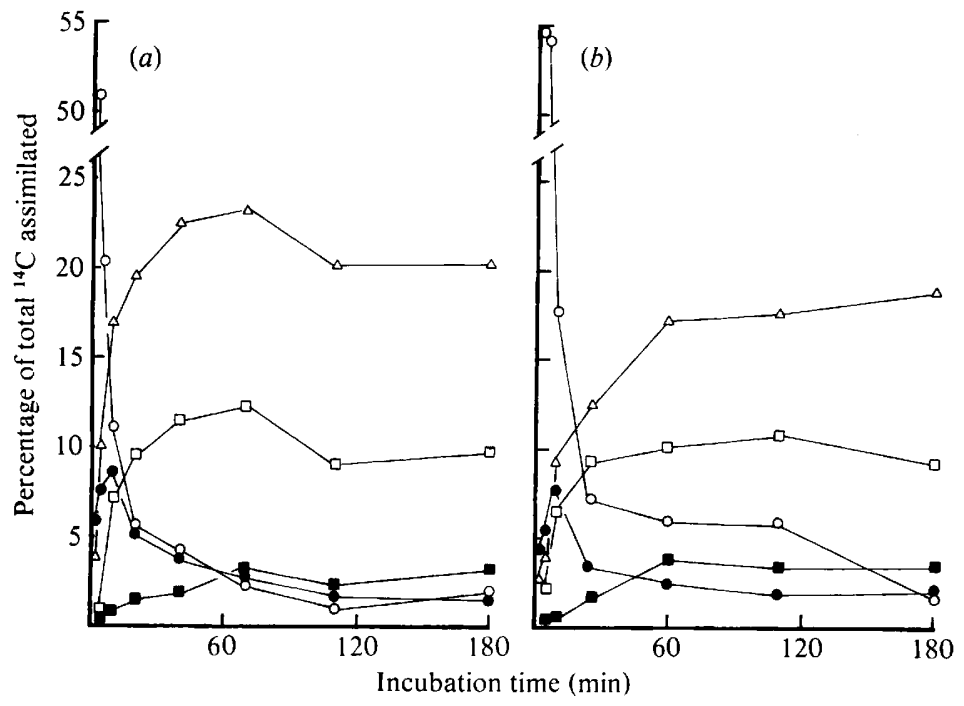

Fig. 3. Distribution of radioactivity between ethanol-soluble carbohydrates after incubation of $P$. graminis in (a) $1 \mathrm{~mm}$ exogenous $\left[{ }^{14} \mathrm{C}\right]$ glucose or $(b) 20 \mathrm{~mm}$ exogenous $\left[{ }^{14} \mathrm{C}\right]$ glucose (see Methods for experimental details). $\bigcirc$, Glucose; $\odot$, fructose; $\square$, glucitol; $\square$, mannitol; $\triangle$, trehalose.

$1 \mathrm{~h}$. Less label was incorporated into mannitol, with an eight- to fifteenfold excess of glucitol after $10 \mathrm{~min}$, and a threefold excess after $3 \mathrm{~h}$.

GLC analyses (cf. legend to Fig. 4) showed no significant changes in the concentrations of any sugar or polyol during the experiment, indicating that labelling was carried out under essentially steady-state conditions. No significant changes were detected in the specific activities of intracellular glucose at any time point, with mean values $\left( \pm\right.$ S.D.) of $13.4 \pm 3.0$ d.p.m. ng $^{-1}$ and $4.4 \pm 2.7$ d.p.m. $\mathrm{ng}^{-1}$ for mycelium incubated in 1 and $20 \mathrm{~mm}$ glucose, respectively. Specific activities of all other sugars and polyols increased more slowly and eventually approached values similar to intracellular glucose (Fig. $4 a, b$ ), and thus reached only 12 and $47 \%$ of the respective specific activities of exogenous glucose.

Specific activities of fructose increased more rapidly than glucitol, mannitol and trehalose and showed no lag period (Fig. 4). However, the kinetics of ${ }^{14} \mathrm{C}$ incorporation into glucitol, mannitol and trehalose showed an initial lag (Fig. $4 c, d$ ) during which the specific activities of glucitol and trehalose rose more rapidly than mannitol. After about $30 \mathrm{~min}$ the specific activities of mannitol increased considerably and reached values similar to those of glucitol.

\section{Incorporation of radioactivity into anions}

After chromatography of anionic fractions in Solvent 2, almost all of the label remained near the origin except for a trace amount which migrated to the same position as gluconic acid. After phosphatase treatment of compounds near the origin, predominantly neutral compounds were released at early time points, whereas after about $80 \mathrm{~min}$ anions began to predominate (Fig. 5). Chromatography of neutral compounds released by phosphatase revealed most radioactivity in trehalose $(>85 \%)$, with traces in glucose and occasionally fructose; results from the 2 min sample (Fig. 6a) are typical. Thus, the kinetics of ${ }^{14} \mathrm{C}$ incorporation into neutral sugar phosphates (Fig. 5) are essentially incorporation into trehalose phosphate.

Rechromatography of anions retaining charge after phosphatase treatment showed most radioactivity remained in positions similar to TCA cycle intermediates (citric, malic and fumaric acids, Fig. $6 b, c$ ); no attempts were made to confirm the identity of these compounds. However, earlier samples (e.g. 10 min, cf. Fig. $6 b$ ) yielded a peak with identical mobility to gluconic acid, indicating a phosphate ester of gluconate. 

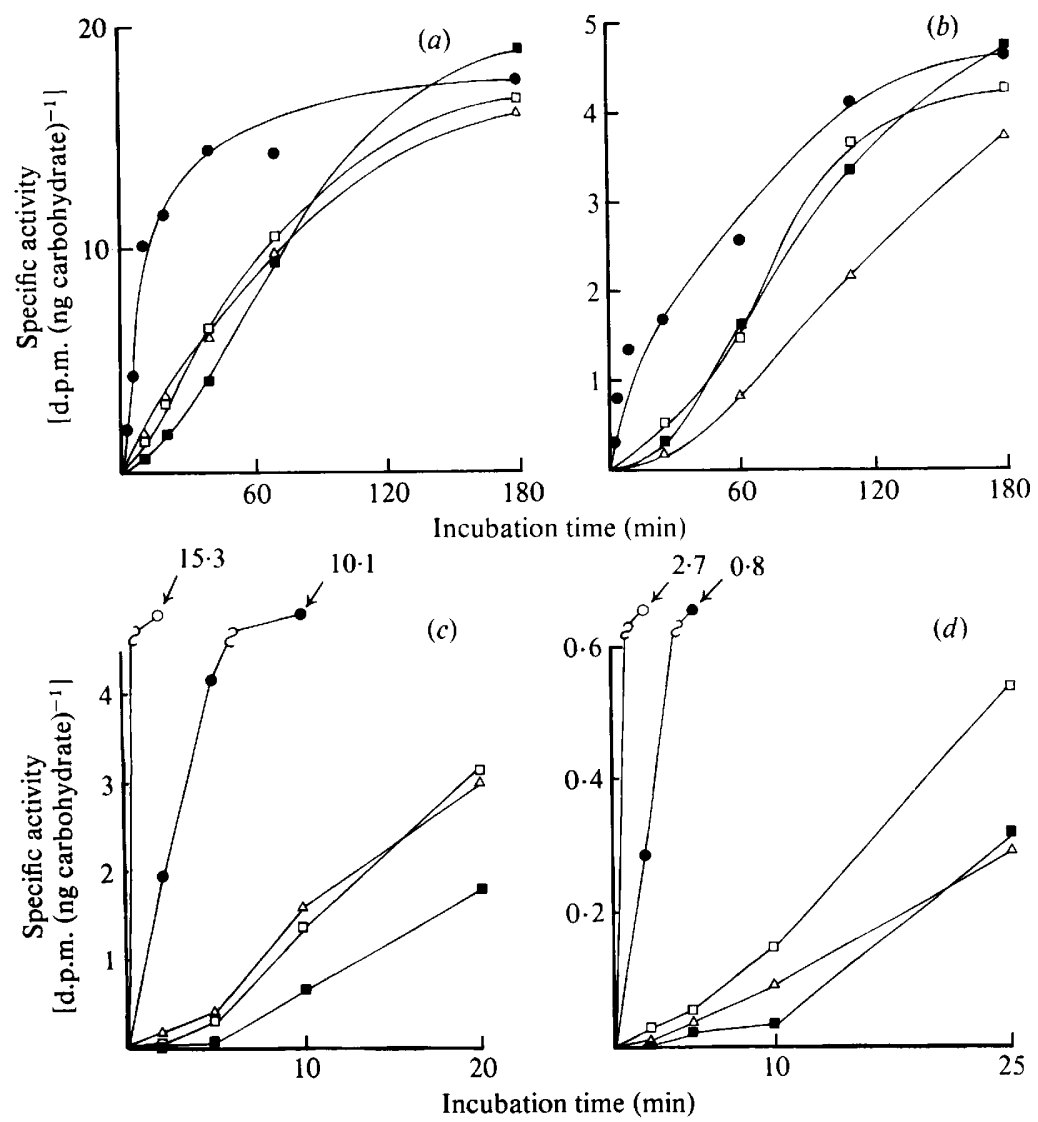

Fig. 4. Specific activities of intracellular pools of carbohydrates during the assimilation of $1 \mathrm{~mm}(a$ and $c$ ) and $20 \mathrm{~mm}(b$ and $d)$ exogenous $\left[{ }^{14} \mathrm{C}\right]$ glucose (see Fig. 1 and Methods for experimental details). Pool sizes [ $\mathrm{mg}\left(\mathrm{g}\right.$ dry $\mathrm{wt}^{-1}$ ] estimated by GLC are indicated in parentheses for 1 and $20 \mathrm{~mm}$ glucose, respectively. $O$, Glucose $(0.37$ and 0.67$) ; O$, fructose $(0.22$ and 0.49$) ; \square$, glucitol $(2.06$ and 3.30$)$; mannitol $(0.54$ and 1.09$) ; \triangle$, trehalose $(4.26$ and 8.75$)$. Specific activities of exogenous glucose at the start of the radiolabelling period were 140 d.p.m. $\mathrm{ng}^{-1}(1 \mathrm{mM})$, and 9.6 d.p.m. $\mathrm{ng}^{-1}(20 \mathrm{mM})$, respectively.

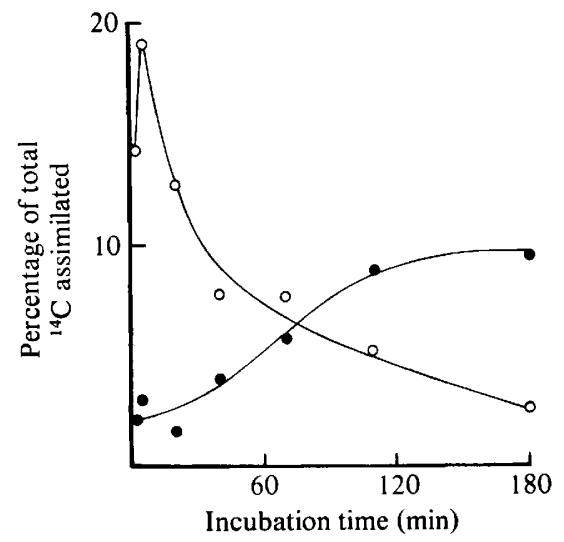

Fig. 5. Distribution of radioactivity between phosphate esters of neutral sugars $(O)$ and other anions (O) during the assimilation of $1 \mathrm{~mm}$ exogenous $\left[{ }^{14} \mathrm{C}\right]$ glucose (see Fig. 1, Methods and Results for experimental and analytical details). 


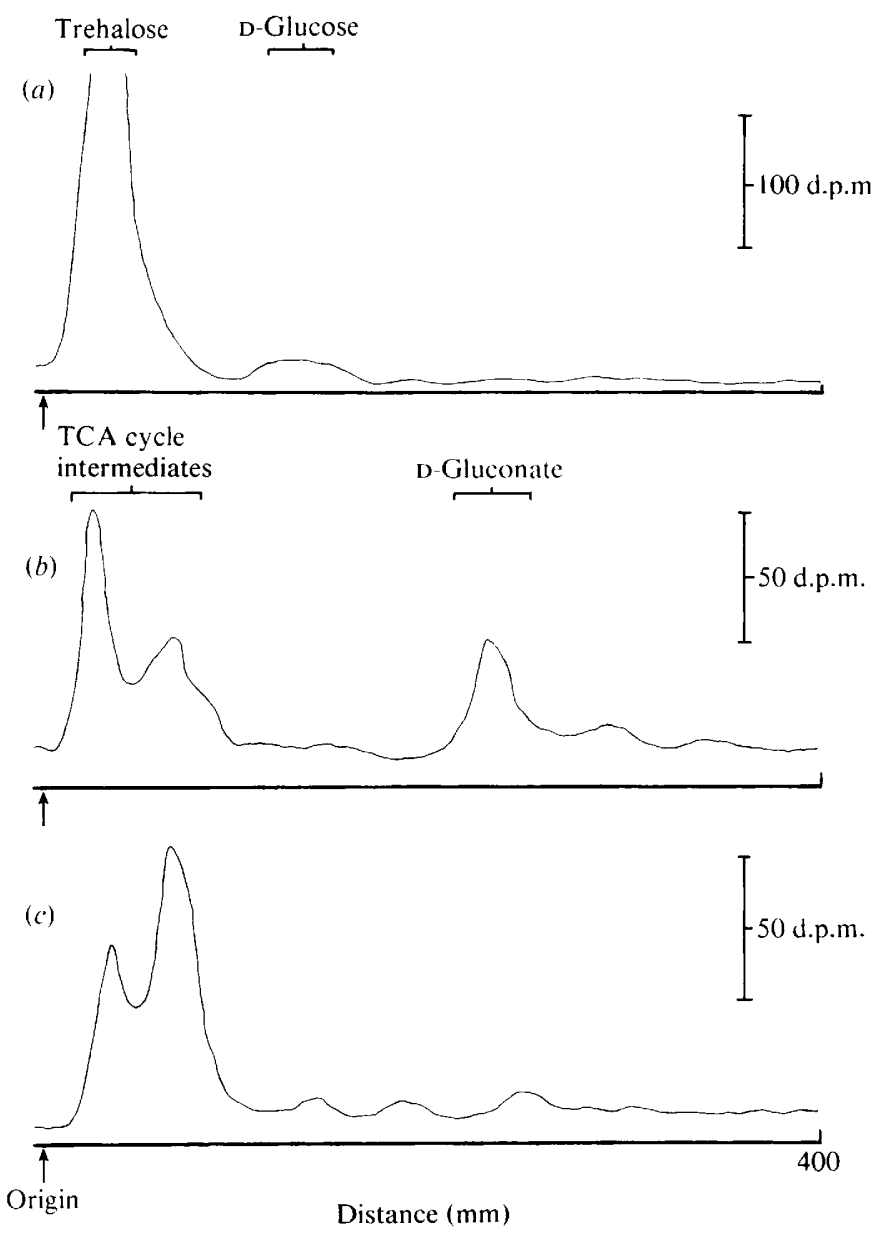

Fig. 6. Chromatographic analysis of ethanol-soluble anions extracted from mycelium after incubation in $1 \mathrm{~mm}\left[{ }^{14} \mathrm{C}\right]$ glucose. Radioactivity was detected using a Nuclear Chicago strip counter after development in appropriate solvent systems (see Methods). (a) Neutral compounds remaining after phosphatase treatment of the total anion fraction obtained 2 min after adding the label. $(b)$ and $(c)$ Compounds which retained anionic charge after phosphatase treatment of the total anion fractions obtained $10 \mathrm{~min}(b)$ and $110 \mathrm{~min}(c)$ after adding the label. Solvent 1 was used for $(a)$ and Solvent 2 for $(b)$ and $(c)$. The positions of authentic standards run on the same chromatograms are shown. 'Tricarboxylic acid (TCA) cycle intermediates' represents succinic, fumaric and malic acids, each of which produced a broad spot over the position indicated.

\section{Incorporation of radioactivity into cations}

At each time point investigated more than $80 \%$ of the label in cations was located in two major peaks on chromatograms, corresponding to (i) glutamic and/or cysteic acids and (ii) alanine and/or glutamine (Table 1). The peak corresponding to glutamic and/or cysteic acids showed a decrease after $10 \mathrm{~min}$ indicating turnover, whereas the peak corresponding to alanine and/or glutamine continued to increase, suggesting accumulation into a storage pool.

\section{DISCUSSION}

Results obtained during this investigation indicate that low (1-20 mM) concentrations of $\mathrm{D}$ glucose are assimilated by pathways involving phosphorylation, isomerization and reduction as primary metabolic events. 
Table 1. Conversion of $\left[{ }^{14} \mathrm{C}\right]$ glucose to amino acids

The fungus was incubated in 1 or $20 \mathrm{~mm}$ [U-14 C]-D-glucose as described in Fig. 1, and samples taken for analysis as described in the Methods.

\begin{tabular}{|c|c|c|c|c|c|c|}
\hline \multirow[b]{4}{*}{ Amino acid } & \multicolumn{6}{|c|}{ Percentage of total cellular radioactivity } \\
\hline & \multicolumn{3}{|c|}{$1 \mathrm{~mm}\left[{ }^{14} \mathrm{C}\right]$ Glucose } & \multicolumn{3}{|c|}{$20 \mathrm{~mm}\left[{ }^{14} \mathrm{C}\right]$ Glucose } \\
\hline & \multicolumn{3}{|c|}{ Incubation time $(\mathrm{min})$ : } & \multicolumn{3}{|c|}{ Incubation time $(\mathrm{min})$ : } \\
\hline & 2 & 10 & 110 & 2 & 10 & 110 \\
\hline Aspartic acid & $1 \cdot 7$ & $1 \cdot 8$ & 0.5 & ND & ND & $0 \cdot 1$ \\
\hline Glutamic plus cysteic acid & $6 \cdot 3$ & $13 \cdot 8$ & $5 \cdot 7$ & $5 \cdot 4$ & $10 \cdot 9$ & $5 \cdot 7$ \\
\hline Alanine plus glutamine & $9 \cdot 6$ & $16 \cdot 2$ & $23 \cdot 2$ & $8 \cdot 8$ & $15 \cdot 9$ & $28 \cdot 2$ \\
\hline Valine plus methionine & $1 \cdot 3$ & $1 \cdot 8$ & $1 \cdot 3$ & 1.9 & $2 \cdot 3$ & 0.8 \\
\hline Other cations & $0 \cdot 6$ & $0 \cdot 4$ & $1 \cdot 2$ & $0 \cdot 2$ & $0 \cdot 3$ & $0 \cdot 1$ \\
\hline Total cations & $19 \cdot 5$ & $34 \cdot 0$ & 31.9 & $16 \cdot 3$ & $29 \cdot 4$ & 34.9 \\
\hline
\end{tabular}

\section{Assimilation via phosphorylated intermediates}

Quantitatively, phosphorylation of glucose appears to be the major primary step in the assimilation of glucose because metabolites of hexose phosphates contained considerable amounts of assimilated radioactivity at the earliest times after adding exogenous $\left[{ }^{14} \mathrm{C}\right]$ glucose. Thus, 2 min after adding label, trehalose phosphate, free trehalose, and amino acids contained about $80 \%$ of the radioactivity present in metabolites of glucose. Because phosphates of glucose and fructose contained only traces of radioactivity they constituted small, rapidly turning-over pools, which, like the intracellular pool of free glucose, became saturated with label within 2 min of adding $\left[{ }^{14} \mathrm{C}\right]$ glucose. The lack of a lag of incorporation of label into trehalose phosphate or amino acids shows that pools of sugar phosphates quickly reached isotopic equilibrium.

\section{Assimilation via fructose}

The rapid appearance of label in free fructose would be difficult to detect in infected plant material, because fructose of host origin would obscure fungal fructose. The kinetic data were consistent with two possible routes of synthesis of fructose: (1) by direct isomerization from glucose as demonstrated in prokaryotes (Suekane et al., 1978; Chen et al., 1979) or (2) from fructose-6-phosphate by phosphatase activity. The pathway of fructose synthesis via glucitol demonstrated in animal systems (Hers, 1960; Touster \& Shaw, 1962) can be discounted because label accumulated in fructose prior to glucitol (cf. Figs 3 and 4). Synthesis of fructose via sugar phosphates would waste energy with no apparent advantage to the fungus. However, aerial hyphae of Melampsora lini after $4 \mathrm{~h}$ incubation in specifically labelled glucose showed labelling of fructose consistent with some synthesis via the pentose phosphate pathway (Mitchell \& Shaw, 1968). Further research is necessary to elucidate pathways of fructose synthesis in rust fungi.

\section{Synthesis of glucitol and mannitol}

Despite many analyses of carbohydrates in rust fungi by previous workers, few have detected glucitol, and careful attention to technique is necessary to resolve glucitol from mannitol, even in defatted and deionized extracts (Fig. 2), as discussed by Maclean (1982).

Kinetic data are consistent with glucitol being synthesized from both glucose and fructose, but with mannitol being synthesized only from fructose. Fructose took up label without lag and prior to each hexitol (Fig. 4). The role of fructose as a precursor of glucitol is evident from the lag in movement of label into glucitol, which would not be expected if glucitol was only synthesized from the more rapidly labelled glucose pool. However, at early time points label moved into glucitol prior to mannitol (Fig. 4), indicating an additional precursor pool such as glucose that was labelled at a faster rate than fructose. The accumulation of 2-deoxyglucitol after feeding 2-deoxyglucose (Manners et al., 1981) is also consistent with glucose being a precursor of glucitol. 


\section{Synthesis of trehalose}

Using cell-free extracts of Saccharomyces cerevisiae, Cabib \& Leloir (1958) showed trehalose synthesis via glucose-6-phosphate, UDPG and trehalose phosphate. Our in vivo experiments with $P$. graminis are consistent with this pathway, because trehalose phosphate accepted label prior to trehalose. Trehalose phosphate constituted the largest pool of sugar phosphates, and the time required to saturate this pool accounts for the lag observed in the synthesis of trehalose (Fig. 4). Total label in free plus phosphorylated trehalose accumulated linearly with time, indicating a common origin from small, rapidly turning-over pools of glucose phosphates and sugar nucleotides.

\section{Sources of carbon in sugar and polyol pools}

Because steady-state specific activities of cellular pools of sugars and polyols were much lower than specific activities of exogenous glucose, a large flow of unlabelled carbon also entered these pools. Possible sources of this unlabelled carbon include exogenous peptone or citrate, or endogenous reserves such as lipids or glycogen. Pathways for mobilizing carbon into free sugars from any of the above sources might have been induced after transfer from $212 \mathrm{~mm}$-glucose (growth medium), and during the $18 \mathrm{~h}$ incubation in the lower concentrations necessary for providing high specific activity $\left[{ }^{14} \mathrm{C}\right]$ glucose to the fungus. The proportion of unlabelled to labelled glucose entering the sugar and polyol pools was greater with $1 \mathrm{~mm}$ than with $20 \mathrm{~mm}$ exogenous glucose, but the kinetics of ${ }^{14} \mathrm{C}$ assimilation into all metabolites were almost identical at each concentration. Therefore, regardless of the source of unlabelled carbon in sugar and polyol pools, the pathway of assimilation of exogenous glucose appears to be the same.

The rapid movement of carbon from exogenous $\left[{ }^{14} \mathrm{C}\right] g l u c o s e$ to amino acids suggests that when $P$. graminis is maintained on low concentrations of glucose, there may be concurrent counterflows of carbon through glycolysis and gluconeogenesis. This would result in the operation of a number of futile cycles (Hue, 1981), and thus waste ATP. If pools of trehalose are turned over, as is suggested by the specific activity of trehalose tending towards that of intracellular glucose, this also would result in wastage of energy, because the two molecules of ATP required for the synthesis of trehalose from free glucose are not recouped during its catabolism by trehalase (Elbein, 1974), or trehalose phosphorylase (Marechal \& Belocopitow, 1972). Such metabolic inefficiency could be a contributing factor to the requirement of $P$. graminis for high glucose concentrations for optimal growth (cf. Maclean, 1974).

J.M.M. was supported by a University of Queensland Postdoctoral Fellowship. Financial assistance from the Australian Research Grants Committee and the Wheat Industry Research Council of Australia is gratefully acknowledged.

\section{REFERENCES}

BRITTON, H. G. (1959). The detection of carbohydrates with silver in the presence of borate. Biochemical Journal 73, 19P.

CABIB, E. \& LeloIR, L. F. (1958). The biosynthesis of trehalose phosphate. Journal of Biological Chemistry 231, 259-275.

Chen, W. P., Anderson, A. W. \& Han, Y. W. (1979). Extraction of glucose isomerase from Streptomyces flavogriseus. Applied Environmental Microbiology 37, 785-787.

ElbEIN, A. D. (1974). The metabolism of $\alpha, \alpha$-trehalose. Advances in Carbohydrate Chemistry and Biochemistry 30, 227-256.

Harborne, J. B. (1973). Phytochemical Methods, 1st edn. London: Chapman and Hall.

Hers, H. G. (1960). Le mécanisme de la formation du fructose séminal et du fructose foetal. Biochimica et biophysica acta 37, 127-138.
Hough, L. \& JoNes, J. K. N. (1962). Chromatography on paper. Methods in Carbohydrate Chemistry 1, 2131.

Howes, N. K. \& SCOTT, K. J. (1973). Sulphur metabolism of Puccinia graminis f.sp. tritici in axenic culture. Journal of General Microbiology 76, 345-354.

HuE, L. (1981). The role of futile cycles in the regulation of carbohydrate metabolism in the liver. Advances in Enzymology and Related Areas of Molecular Biology 52, 247-331.

LEWIS, D. H. (1976). Interchange of metabolites in biotrophic symbioses between angiosperms and fungi. In Perspectives in Experimental Biology, Vol. 2 Botany, p. 207. Edited by N. Sunderland. Oxford: Pergamon Press.

MaClEAN, D. J. (1974). Cultural and nutritional studies on variant strains of the wheat stem rust fungus. Transactions of the British Mycological Society 62, 333-349. 
MaClean, D. J. (1982). Axenic culture and metabolism of rust fungi. In The Rust Fungi, pp. 37-120. Edited by K. J. Scott \& A. K. Chakravorty. London: Academic Press.

Maclean, D. J. \& ScotT, K. J. (1970). Variant forms of saprophytic mycelium grown from uredospores of Puccinia graminis f.sp. tritici. Journal of General Microbiology 64, 19-27.

MACLEAN, D. J. \& SCOTT, K. J. (1976). Identification of glucitol (sorbitol) and ribitol in a rust fungus, Puccinia graminis f.sp. tritici. Journal of General Microbiology 97, 83-89.

Manners, J. M., Maclean, D. J. \& Scott, K. J. (1981). Carbohydrate metabolism in axenic cultures of Puccinia graminis. Abstract of the 13th International Botanical Congress, Sydney, Australia, p. 236.

Marechal, L. R. \& Belocopitow, E. (1972). Metabolism of trehalose in Euglena gracilis. I. Partial purification and some properties of trehalose phosphorylase. Journal of Biological Chemistry 247, 32233228.

Mitchell, D. \& Shaw, M. (1968), Metabolism of glucose ${ }^{14} \mathrm{C}$, pyruvate- ${ }^{14} \mathrm{C}$, and mannitol- ${ }^{14} \mathrm{C}$ by Melampsora lini II. Conversion to soluble products. Canadian Journal of Botany 46, 453-460.

Neal, G. E. \& Beevers, H. (1961). Pyruvate utilization in castor bean endosperm and other tissues. Biochemical Journal 74, 409-416.

Pfyffer, G. E. \& RAST, D. M. (1980a). Systematic distribution of ribitol in the fungi. New Phytologist 85, $163-168$.

Pfyffer, G. E. \& Rast, D. M. (1980 $b$ ). The polyol pattern of some fungi not hitherto investigated for sugar alcohols. Experimental Mycology 4, 160-170.

REES, W. R. \& REYNOLDS, T. (1958). A solvent for the chromatographic separation of glucose and sorbitol. Nature, London 181, 767-768.

Smith, D., Muscatine, L. \& Lewis, D. (1969). Carbohydrate movement from autotrophs to heterotrophs in parasitic and mutualistic symbiosis. Biological Reviews 44, 17-90.

Suekane, M., Masaki, T. \& Chikaka, T. (1978). Physico-chemical properties and enzymatic properties of purified glucose isomerases from Streptomyces olivochromogenes and Bacillus stearothermophilus. Agricultural and Biological Chemistry 42, 909 918.

Sweeley, C. C., Bentley, R., Makita, M. \& Wells, W. W. (1963). Gas-liquid chromatography of trimethylsilyl derivatives of sugars and related substances. Journal of the American Chemical Society 85 , 2497-2507.

TOUSTER, O. \& SHAW, D. R. D. (1962). Biochemistry of the acyclic polyols. Physiological Reviews 42, 181225.

Trevalyan, W. E., Procter, D. P. \& Harrison, J. S. (1950). Detection of sugars on paper chromatograms. Nature, London 166, 444-445. 